\title{
Incidence and occupational pattern of leukaemias, lymphomas, and testicular tumours in Western Ireland over an 11 year period
}

Cecily Kelleher, John Newell, Collette MacDonagh-White, Emer MacHale, Ernest Egan, Eugene Connolly, Helen Gough, Bettie Delaney, Eithne Shryane
Departments of Health

Promotion and

C Kelleher

J Newell

C MacDonagh-White

H Gough

B Delaney

E Shryane

Haematology and

Pathology

E Egan

E Connolly

National University of Ireland, Galway

Galway Community Care Area, Western Health Board, Galway E MacHale

Correspondence to: Professor C Kelleher, Department of Health Promotion, Clinical Sciences Institute, National University of Ireland, Galway.

Accepted for publication 30 March 1998

\begin{abstract}
Study objective-To determine incidence of the following malignancies, testicular tumours, all leukaemias and all lymphomas in the West of Ireland in an 11 year period. Secondly, to examine the relation between disease patterns and available occupational data in male subjects of working age.
\end{abstract}

Design-A census survey of all cases occurring in the three counties in the Western Health Board (WHB) area, Galway, Mayo and Roscommon, for the 11 year period 1980 to 1990 inclusive. Average annual age standardised incidence rates for the period were calculated using the 1986 census data. Rates for the area are compared with rates from the southern region of Ireland, which had a tumour registry. Trends over the time period are evaluated. All male subjects for whom occupational data were available were categorised using the Irish socioeconomic group classification and incidence rates by occupation were compared using the standardised incidence ratio method. In one of the counties, Galway, a detailed occupational history of selected cases and an age matched control group was also elicited through patients' general practitioners.

Setting-All available case records in the West of Ireland.

Results-There are no national incidence records for the period. Compared with data from the Southern Tumour Registry, the number of cases of women with myeloid leukaemias was significantly lower. Male leukaemia rates were significantly lower as a group (SIR 84 (95\%CI 74, 95) but not when considered as individual categories. Regression analysis revealed an increasing trend in the number of new cases of non-Hodgkin's lymphoma among both men $(r=0.47, p=0.02)$ and women $(r$ $=0.90, p=0.0001)$ and of chronic lymphocytic leukaemia in men $(r=0.77$, $\mathrm{p}=0.005)$ and women $(r=0.68 \mathrm{p}=0.02)$ in the WHB region over the last decade. Four hundred and fifty six male cases over the age of 15 years were identified and adequate occupational information was available for $74 \%$ of these. Standardised incidence ratios of testicular tumours were significantly increased for semiskilled manual workers (SIR 367 95\%CI
$100,938)$ and agriworkers other than farmers ( SIR 377, 95\%CI 103, 967). There were also significantly increased incidence ratios for both non-Hodgkin's lymphoma (SIR 169, 95\%CI 124, 266) and three categories of leukaemias among farmers. Hodgkin's disease and acute myeloid leukaemias were significantly increased among semi-skilled people. Interview data with 90 cases and 54 controls of both sexes revealed that among farmers, cases (n =31) were significantly less likely than controls $(n=20)$ to use tractor mounted spraying techniques $(\mathrm{OR}=0.19(95 \% \mathrm{CI}$ $0.04,0.80)$ ) and less likely to wear protective masks (OR 0.22 (95\%CI 0.05, 0.84)). Conclusions-Trends of increase in nonHodgkin's lymphoma and some leukaemias are consistent with studies elsewhere. The study provides further evidence of the relation between agricultural work and certain lymphoproliferative cancers. The possible carcinogenic role of chemicals used in agricultural industries must be considered as an explanation. (f Epidemiol Community Health 1998;52:651-656)

The importance of morbidity surveillance in relation to malignant disease is undoubted in identifying disease aetiology. The assessment of environmental risk factors for malignant diseases can be particularly problematic because of the long potential interval between exposure and development of disease and the difficulty of adequate biological monitoring of hazards. It is especially so in the case of the working environment where a detailed and comprehensive employment history over a number of years is required and where frequent change of employment can occur, particularly in the case of unskilled and semi-skilled workers. Furthermore, new industries are appearing all the time that involve the management of potentially hazardous substances whose safety track record in relation to human exposure is not yet known in epidemiological terms. There is evidence that some cancers may be increasing in incidence. ${ }^{1}$ In Ireland, farming and agriculture are particularly important, as there are a relatively large proportion of the population employed in this sector at $14 \% .^{2}$ There is increasing emphasis on the development of industries associated with agricultural production and processing and one of these, fish farming, has expanded considerably in the past 10 years. Data on morbidity are difficult to 
ascertain as legislation in relation to health and safety practices was only extended comprehensively to the farming sector in Ireland in 1989. Likewise data about occupation are not always systematically recorded in medical case notes and there may be under-reporting of such information.

This report is the third to examine demographic patterns of malignancy in the West of Ireland. ${ }^{34}$ Incidence and death rates for selected lymphoproliferative disorders are examined but also on this occasion testicular tumours. The findings over the 11 year period of this study are compared with Southern Tumour Registry data and with the results of the previous study. This study was instigated originally because of an anecdotal clinical observation that there appeared to be an undue number of cases with testicular tumours or leukaemia in workers associated with fish farming industry, an issue that needed to be more systematically investigated. All such cases first had to be identified by a census survey of the three counties constituting the Western Health Board area. The incidence over an 11 year period of the candidate neoplasms and their relation with occupation is reported.

\section{Methods}

This study was a census of all available data in the three counties, Galway, Mayo, and Roscommon for the 11 consecutive years 1980 to 1990 inclusive. The total population of the area at the midpoint of the period was 348328 , $51 \%$ of whom were men. At the time this study was undertaken the National Tumour Registry had not yet been established, so that no national morbidity data were available for that period apart from the data described here and those collected in the former Southern Tumour Registry, comprising counties Cork and Kerry. ${ }^{5}$ The work was overseen by a project steering committee representing the departments of Health Promotion, Haematology and Pathology at University College Galway and the community care area of the Western Health Board. Actual data collection was undertaken by a researcher (HG) with the assistance of two registered nurses (BD and $\mathrm{ES}$ ).

Detailed checking of all known cases of testicular tumours and of leukaemias and lymphomas was undertaken. Permission to proceed was sought from the university hospital ethical committee and from both medical and administrative personnel in each institution. Data sources identified in advance were (a) hospital records, which included University College Hospital, Galway and all other hospitals in the area, (b) death registers for each district, and (c) records of all general practitioners in the WHB area.

Firstly, all medical personnel dealing with such cases were contacted and asked to complete a comprehensive questionnaire giving details of cases known to them. These were then cross checked by the researchers to identify any duplication of information. The researchers also examined each individual laboratory record and confirmed demographic information by checking hospital charts. Origi- nal records for all cases were histologically re-confirmed by either the consultant haematologist or pathologist dealing with the case to confirm the diagnosis as assigned before entry to the database.

In each case, the following variables were recorded, if available: name, current age, current postal address, sex, occupation, specific malignancy type, date of diagnosis, and date of death, if the patient was now deceased. In addition address at time of diagnosis was recorded. As far as possible the present whereabouts of every patient was established and death, if it had occurred, was documented. All general practitioners registered with the Western Health Board were contacted to establish what they knew of long term outcome of individual patients, particularly where data appeared inadequate from the hospital notes. It was recognised that patients ordinarily resident in the West of Ireland might possibly be referred outside the area for treatment so that general practitioners were asked to provide data on such referrals, if any. Access to a testicular tumour registry supported by the Irish Cancer Society was also afforded and all those records were cross checked by a researcher (HG) against our own records. Likewise referral from neighbouring health board counties into the area might occur and if such cases were identified they were excluded. The research nurses then further cross checked all information recorded from these several sources to assemble the database. In effect, however, negligible additional case information not already available through the primary sources listed above was identified.

The data from the 1986 census for the three counties were used to provide denominator data, for three reasons. ${ }^{6}$ Firstly, although preliminary results from the 1991 census were available at the time of analysis these were not sufficiently detailed for our purposes. Secondly, 1986 is a convenient mid time point for the decade as a whole. Finally, detailed sociodemographic breakdown by district electoral division was possible using data specifically provided for the purpose by the Central

Table 1 Average annual crude (CR) and age standardised (ASR) incidence rates/100 000 population during the period 1980-90 for the Western Health Board (WHB) region and the Southern Tumour Registry (STR) and standardised incidence ratios (SIR) with $95 \%$ confidence intervals

\begin{tabular}{|c|c|c|c|c|c|}
\hline & \multicolumn{2}{|c|}{ STR } & \multicolumn{3}{|c|}{$W H B$} \\
\hline & $C R$ & $A S R$ & $C R$ & $A S R$ & SIR $95 \% C I$ \\
\hline Testicular tumours & 2.9 & 2.9 & 2.4 & 2.4 & $86(22,206)$ \\
\hline \multicolumn{6}{|c|}{ Hodgkin's disease } \\
\hline Male & 4.2 & 4.1 & 2.1 & 1.9 & $51(10,149)$ \\
\hline Female & 2.3 & 1.9 & 0.9 & 1.0 & $40(3,162)$ \\
\hline \multicolumn{6}{|c|}{ Non-Hodgkin's lymphoma } \\
\hline Male & 8.5 & 7.3 & 6.2 & 4.8 & $62(31,110)$ \\
\hline Female & 7.6 & 5.9 & 3.8 & 2.8 & $48(18,101)$ \\
\hline \multicolumn{6}{|c|}{ Acute and chronic lymphocytic leukaemia } \\
\hline Male & 6.0 & 4.8 & 6.8 & 5.1 & $101(54,173)$ \\
\hline Female & 3.9 & 2.8 & 4.2 & 2.9 & $103(43,207)$ \\
\hline \multicolumn{6}{|c|}{ Acute myeloid leukaemia } \\
\hline Male & 4.3 & 3.6 & 1.9 & 1.4 & $37(8,102)$ \\
\hline Female & 3.7 & 3.1 & 0.9 & 0.7 & $22(2,80)$ \\
\hline \multicolumn{6}{|l|}{ Other leukaemia } \\
\hline Male & 0.0 & 0.0 & 0.5 & 0.5 & - \\
\hline Female & 0.2 & 0.1 & 0.2 & 0.1 & $75(1,113)$ \\
\hline
\end{tabular}




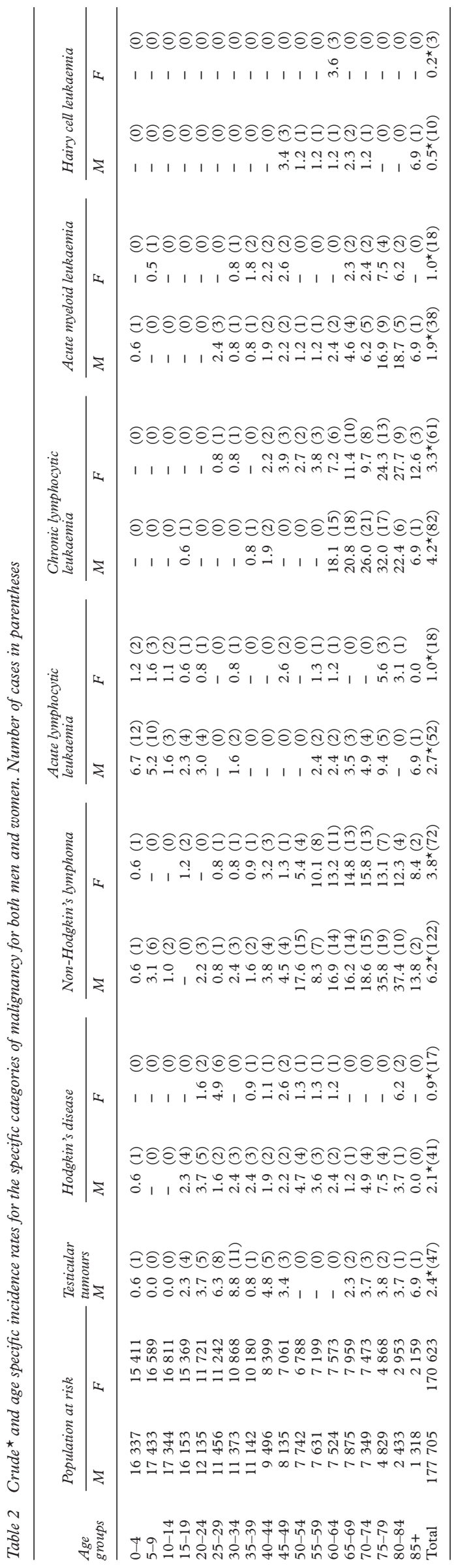

Statistics Office (CSO). Subjects were first categorised according to age, sex, and geographical location for the time period as a whole and comparisons undertaken. Cancers were classified and coded for analysis according to the standard ICD 9 (International Classification of Diseases) as testicular, lymphomas of either Hodgkin's (HD) or non-Hodgkin's lymphoma in variety. Leukaemias were organised in the following subcategories according to that classification system; acute lymphocytic leukaemia (ALL), chronic lymphocytic leukaemia (CLL), hairy cell leukaemia, acute myeloid leukaemia (AML)/acute non-lymphoid leukaemia (ANLL), and chronic granulocytic leukaemia (CGL).

Occupation was also recorded, if available from case notes. Where such was not recorded on the patient's chart the information was subsequently sought from the general practitioner. Occupation was classified using the Irish socioeconomic classification. ${ }^{7}$ Occupations are first categorised into socioeconomic groups (SEGs), a nominal classification, and can be further organised and ranked according to a class scale. For the purposes of this part of the study, although information on both sexes was collected, it was decided a priori to examine male occupational data only because the population of primary interest was the working one and data for men were considered to be more reliable.

As no detailed exposure data were available in case notes it was also decided to survey a sub-section of cases with half as many age matched controls. All cases of testicular tumours, and of leukaemia and lymphoma cases of both sexes aged between 16 and 65 at diagnosis in one of the counties, Galway, were identified. One hundred and twenty five cases (M: 75; F: 50) were identified but 16 of these had no listed general practitioner and so were not considered further. Forty three of the remainder had died. Permission was sought from the local faculty of the Irish College of General Practitioners to have the general practitioner interview these patients, if still alive, or their relatives, if deceased, about their exposure history. A questionnaire was designed and piloted for the study that included details of all past residences, past medical history, reproductive history, occupational history, and chemical exposures at work and at home, including the garden. A specific section for farmers detailed manner of use of pesticides. Controls were to be selected through two general practices, one within five miles of the city and one rural, felt to be sociodemographically representative of the region as a whole. Patients presenting to these practices during the study period for a routine consultation who were in the right age group were asked to complete the questionnaire with their doctor.

STATISTICAL ANALYSIS

Average annual rates per 100000 were calculated using the direct method and standardised to the World Standard Population. Significance comparison by region and occupation was by the standardised incidence ratio method, using 


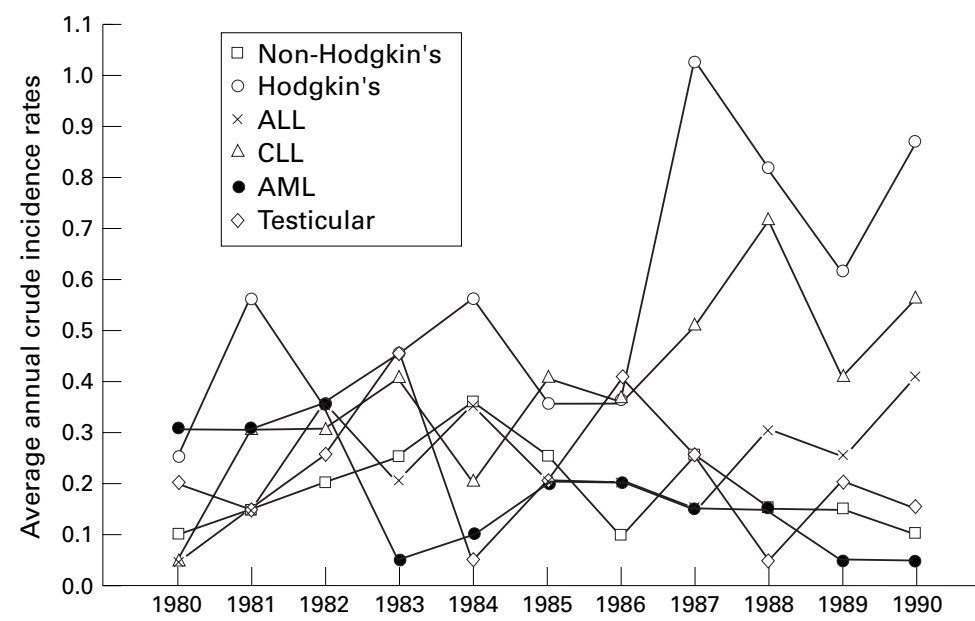

Figure 1 Male average annual crude incidence rates for selected disorders in the WHB from 1980-1990 using the CSO 1986 data.

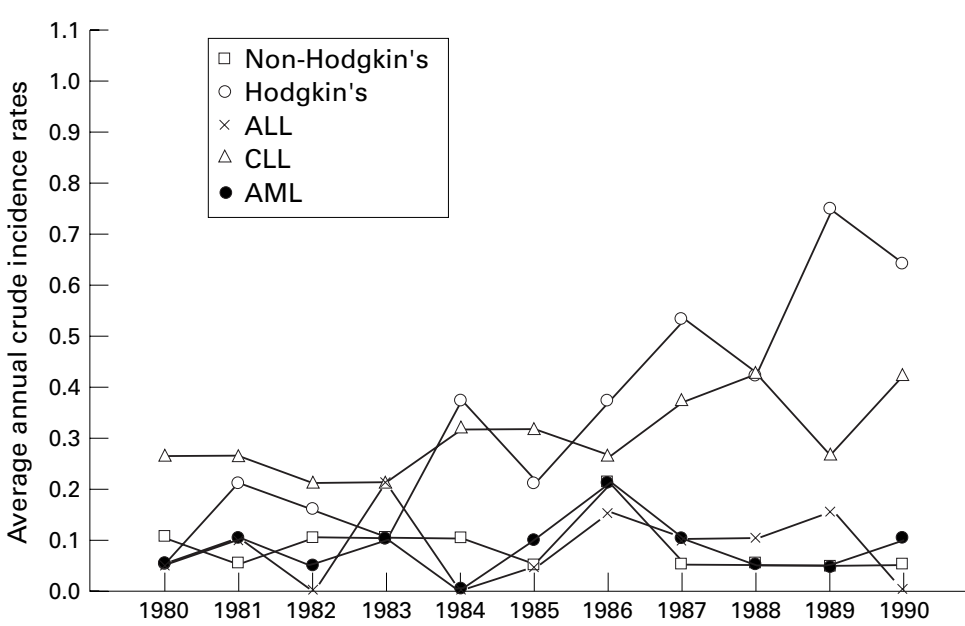

Figure 2 Female average annual crude incidence rates for selected disorders in the WHB from 1980-1990 using the CSO 1986 data.

the appropriate 1986 census data as the denominator. ${ }^{89}$ Trends over time were evaluated using regression modelling. Statistical comparison of the interview findings was by means of odds ratio.

\section{Results}

In all, 683 records were identified and confirmed, of which $456(67 \%)$ were male cases. Information on current status was mainly from hospital records ( $79 \%$ of cases). A
KEY POINTS

- Non-Hodgkin's lymphoma and chronic lymphocytic leukaemia rates appear to be rising in incidence in the West of Ireland.

- Farmers demostrate increased incidence ratios for non-Hodgkin's lymphoma and three categories of leukaemias, in keeping with studies elsewhere.

- Farm hygiene practice, particularly in handling chemicals during spraying and use of protective clothing, may be a factor and if so this merits more attention in health education programmes.

further 47 cases were found at death registry to have died and a small number of cases, $6 \%$ of the total, were identified by general practitioners who had not been previously detected through the hospital records or death registry. The total number of cases in each category was 47 testicular tumours, 252 (65\% male) lymphomas, and 384 ( $64 \%$ male) leukaemias.

The average age adjusted incidence rate of these cancers for the 11 year period in the WHB was compared with the figures produced from the National Tumour Registry based on the Southern Health Board data. ${ }^{5}$ Table 1 shows crude and age standardised rates for both areas. The standardised incidence ratio (SIR) for leukaemias as a whole is reduced in men (SIR 84, 95\%CI 74, 95) but when broken down into individual categories this is no longer significant. Though all categories apart from lymphocytic leukaemias have lower SIRs, there are no significant differences apart from female rates of myeloid leukaemias, which are lower in the WHB area.

Table 2 shows the detailed age specific incidence rates in five year bands for individual categories of leukaemias and lymphomas. The pattern for testicular cancers is bi-modal with highest rates seen in the age category 30-34 years. The tendency for increased rates with age is confirmed in the case of both the leukaemia and lymphoma categories.

In examining the data over the 11 year time period, (figs 1 and 2), regression analysis revealed an upward trend in both men ( $r$ $=0.47, \mathrm{p}=0.02)$ and women $(r=0.90$, $\mathrm{p}=0.0013)$ for non-Hodgkin's lymphoma and

Table 3 Standardised incidence ratios by occupation with 95\% confidence intervals for each category of malignancy in all men with recorded occupational information. Note a very large upper value for confidence interval is represented as a symbol. Number of cases ( $n$ ) in parentheses

\begin{tabular}{|c|c|c|c|c|c|c|c|c|}
\hline$S E G$ & Men at risk & $\begin{array}{l}\text { Testicular } \\
(n=33)\end{array}$ & $\begin{array}{l}\text { Hodgkin's disease } \\
(n=32)\end{array}$ & $\begin{array}{l}\text { Non-Hodgkin's } \\
\text { lymphoma } \\
(n=83)\end{array}$ & $\begin{array}{l}\text { Acute } \\
\text { lymphocytic } \\
\text { leukaemia } \\
(n=31)\end{array}$ & $\begin{array}{l}\text { Chronic } \\
\text { lymphocytic } \\
\text { leukaemia } \\
(n=65)\end{array}$ & $\begin{array}{l}\text { Acute myeloid } \\
\text { leukaemia } \\
(n=32)\end{array}$ & $\begin{array}{l}\text { Hairy cell } \\
\text { leukaemia } \\
(n=9)\end{array}$ \\
\hline Farmers & 53971 & $65(26,133)$ & $143(80,263)$ & $169(124,266)$ & $187(113,292)$ & $188(134,256)$ & $181(109,283)$ & $203(75,443)$ \\
\hline Other/agriculture & 5289 & $377(103,967)$ & $97(5,+)$ & & $100(6,+)$ & & & \\
\hline Higher professional & 5533 & $90(5,+)$ & $279(58,816)$ & $215(79,468)$ & $192(7,+)$ & $46(2,+)$ & & \\
\hline Lower professional & 7032 & $284(1,+)$ & $293(80,750)$ & $169(62,369)$ & $76(4,+)$ & $180(59,420)$ & $146(5,+)$ & \\
\hline Self employed & 8583 & & & $116(38,270)$ & & $236(102,465)$ & $180(37,526)$ & $213(12,+)$ \\
\hline Salaried & 3044 & & $169(9,+)$ & $65(1,+)$ & & & & \\
\hline $\begin{array}{l}\text { Intermediate } \\
\text { non-manual }\end{array}$ & 14563 & $103(21,300)$ & $71(3,+)$ & $68(22,159)$ & $109(22,320)$ & $70(19,178)$ & $35(2,+)$ & $126(7,+)$ \\
\hline Other non-manual & 13902 & $72(3,+)$ & & $71(23,167)$ & & & $37(2,+)$ & \\
\hline Skilled manual & 34057 & $103(41,211)$ & $30(1,+)$ & $35(1,376)$ & $62(17,160)$ & $37(1,287)$ & $30(1,+)$ & $54(3,+)$ \\
\hline Semi-skilled & 5447 & $367(100,938)$ & $378(103,968)$ & $109(25,319)$ & $98(5,+)$ & $93(3,+)$ & $378(103,968)$ & \\
\hline $\begin{array}{l}\text { Unskilled manual } \\
\text { workers }\end{array}$ & 13291 & $38(2,+)$ & & & & & & \\
\hline Total & 164712 & 100 & 100 & 100 & 100 & 100 & 100 & 100 \\
\hline
\end{tabular}


Table 4 Responses to pesticide use and practice among interview participants with a farming occupation. Note that there may be more than one positive response per person

\begin{tabular}{|c|c|c|c|c|c|c|c|c|c|c|}
\hline & \multicolumn{6}{|c|}{ Cases 31 of 90} & \multirow{2}{*}{\multicolumn{3}{|c|}{ Controls 20 of 54}} & \multirow{3}{*}{$\begin{array}{l}\text { Odds ratio } \\
\text { for difference } \\
-(95 \% \mathrm{CI}) \\
\text { cases/controls }\end{array}$} \\
\hline & \multicolumn{3}{|l|}{ Men } & \multicolumn{2}{|l|}{ Women } & \multirow[b]{2}{*}{ All } & & & & \\
\hline & Testicular & Leukaemias & Lymphomas & Leukaemias & Lymphomas & & Men & Women & All & \\
\hline All & 7 & 6 & 10 & 5 & 3 & & 12 & 8 & & \\
\hline \multicolumn{11}{|l|}{ Method of application } \\
\hline Tractor mounted & 2 & 2 & 2 & 0 & 0 & 6 & 8 & 3 & 11 & $0.19(0.04,0.80)$ \\
\hline Hand held & 1 & 2 & 3 & 1 & 0 & 7 & 3 & 2 & 5 & $0.87(0.19,4.18)$ \\
\hline Back pack & 6 & 1 & 5 & 4 & 3 & 19 & 5 & 2 & 7 & $2.94(0.79,11.25)$ \\
\hline \multicolumn{11}{|l|}{ Protective equipment } \\
\hline Overalls & 1 & 1 & 2 & 0 & 0 & 4 & 1 & 2 & 3 & $0.83(0.12,6.46)$ \\
\hline Gloves & 2 & 1 & 2 & 1 & 0 & 6 & 3 & 3 & 6 & $0.56(0.12,2.56)$ \\
\hline Mask & 2 & 2 & 2 & 2 & 1 & 9 & 8 & 5 & 13 & $0.22(0.05,0.84)$ \\
\hline
\end{tabular}

similarly for chronic lymphocytic leukaemia in both sexes $(r=0.77, \mathrm{p}=0.005$ and $r=0.68$, $\mathrm{p}=0.02$ respectively). Acute myeloid leukaemia appeared to be declining in men $(r=0.71, \mathrm{p}=$ $0.01)$. Testicular tumours display no definite trend.

Four hundred and fifty six male cases over the age of 15 years at diagnosis were identified and codable occupational data were available for $74 \%$ of these. Rates in men for each socioeconomic group were computed using the appropriate census denominator data. Table 3 gives the SIRs with $95 \%$ confidence intervals for each SEG. It can be seen that testicular tumours were significantly more likely to occur in agricultural workers other then farmers and among semi-skilled persons. There were just five cases however, though four were fish farmers. The farmer category was particularly notable in having significantly higher ratios in four of the seven categories. The semi-skilled group also had higher rates of testicular tumours, Hodgkin's disease, and acute myeloid leukaemia. Overall, there was no pattern of geographical association between testicular cancers and any relevant industries in the region.

Interview data on previous chemical exposure were obtained for 90 cases $(82.6 \%)$. Reasons for non-participation included no next of kin available (7), refusal (5) or non-response from next of kin (5). Data were collected from 54 controls, with no refusals to participate. One author $(\mathrm{CMcDW})$ interviewed approximately half of the cases and controls or their relatives, as appropriate, the remainder were interviewed by their own general practitioners. There were no significant differences in reported uses of any specific pesticides between cases and controls, either in an occupational or a domestic setting. Thirty one (M: 23; F: 8) of the cases and 20 (M:12; F: 8) of the controls had worked primarily as a farmer and gave detail of their pesticide application practice (see table 4). Farmer cases were less likely to wear protective masks than control farmers (odds ratio 0.22 $(0.05,0.84))$. Cases were also less likely to spray herbicides using the tractor mounted method (odds ratio $0.19(0.04,0.80)$ ). These differences remained significant when men only were compared. There was no difference between cases and controls in duration of employment as a farmer, acreage of farm, growth of specific crops types, and type of farming.

\section{Discussion}

This study shows no excess of any of these categories of tumours compared with the only other part of the country for which there are contemporary available data and in the case of some tumour types, a lower rate is reported. The main findings were a rise in both sexes in the incidence of non-Hodgkin's lymphoma and chronic lymphocytic leukaemia in the region over time and patterns of association between occupational group and different categories of malignancy. This is in fact an increase in the number of cases ascertained or diagnosed in the 11 year period. In theory more cases could have been treated and referred, accounting for the rise in incidence. However, those with an address outside the Board area were excluded and our clinical treatment practices have not significantly changed during that time. Furthermore, the trends are not seen for every tumour type. Though we used the midpoint census data, the population variations were modest during the time and could not explain the effect. The newly established National Tumour Registry in Ireland can now monitor these effects systematically for the future. For epidemiological purposes, studies of leukaemias and lymphomas tend to group cases according either to end organ disease or cell line. In this study we used the ICD 9 system of categorisation to retain consistency with previous studies in the region. The age specific rates reported in this paper are consistent with the known epidemiology of these diseases.

The reasons for a change in incidence are not clear. Non-Hodgkin's lymphoma has shown a dramatic increase in incidence in the USA in the past 10 to 15 years ${ }^{10}$ compared with Hodgkin's disease. Numerous medical conditions may predispose to non-Hodgkin's lymphoma, and include patients who have been treated with immunosuppressive drugs, ${ }^{11}$ patients who have AIDS, ${ }^{12}$ patients with longstanding infection with Epstein-Barr virus, ${ }^{13}$ patients with coeliac disease, ${ }^{14}$ and patients who have certain autoimmune diseases. ${ }^{15}$ More recently patients who harbour the bacterium Helicobacter pylori in the stomach have been shown to have a higher incidence of gastric lymphoma. ${ }^{16}$ Environmental carcinogens may be more likely to be implicated in the development of nonHodgkin's lymphoma arising primarily in the lymph nodes, in contrast with those that arise at extranodal sites such as occur in patients who are immunosuppressed and that seem to 
be linked to the Epstein-Barr virus. The vast majority of cases of non-Hodgkin's lymphoma reported in this study are nodal in type.

Other factors implicated in the medical literature include exposure to a wide range of agricultural chemicals ${ }^{17}{ }^{18}$ used in farming and forestry and also exposure to various solvents used in the construction and paper industry. Exposure to toxic hazards, particularly at work are therefore an important aetiological possibility for lympho-proliferative tumours. This is rendered more likely if there is inadequate use of appropriate protective equipment or poor hygiene practice. We found an excess of leukaemias and non-Hodgkin's lymphomas among farmers generally but not for other agricultural workers. The finding confirms the trends seen in other studies elsewhere. ${ }^{19-21}$ Our interview data on a small subsample lend support to the conclusion that inappropriate hygiene practices may have a role, though these should be interpreted with caution as numbers were small and there could be some recall bias.

We found a significant increase in testicular tumours in agricultural workers other than farmers, albeit with very small numbers; this group comprised predominantly those engaged in fish farming. Testicular tumours are rare, accounting for only about $1 \%$ of all male neoplasms. ${ }^{22}$ There has been a remarkable $300 \%$ increase in this century in the United Kingdom and European countries generally. Prognosis has improved with treatment however. Cryptorchidism, drugs, and infections are possible aetiological factors. Testicular tumours are reported elsewhere to be rising in incidence in industrialised societies generally, including Ireland. ${ }^{23}{ }^{24}$ The age distribution of these tumours is bimodal however and in the case of young men the environmental hazard may even be pre-natal. The relative risk of male infertility is also increasing, in part attributed to the increased prevalence of chemicals that have oestrogen-like actions. ${ }^{25}$ One study showed an increased risk in both agricultural and petrochemical workers and suggested a viral explanation or some common toxic hazard. ${ }^{26}$ Other studies indicate that the relation to occupation is not consistent, suggesting it may be a confounder for some other aspect of socioeconomic status. ${ }^{27}$

Comparisons were made across a variety of socioeconomic groups and for several different malignancy categories, thus increasing the probability of finding an association. There may be confounding exposures from other sources; for instance fish farm workers may well be engaged in other part time farming work. There is no evidence to date of an increase in this category of testicular malignancies in fish farm workers in other countries that retain adequate occupational surveillance data and have a significant fish farm industry such as Scotland and Scandinavia (personal communications) and there are no confirmatory studies of tumours among the fish themselves, though potential toxicity to Nuvan, the principal agent used to control sea lice infestation has been studied at varying concentrations. ${ }^{28}$ In a country with a strong dependence on agriculture the implications for further occupational surveillance and for attention to work practice, particularly the handling of potentially noxious materials, is clear.

We are grateful to the staff of local hospitals, general practices, and registries in the region who facilitated access to the records.

Funding: this study was undertaken with financial support from the Health Research Board of Ireland and the Western Health Board.

Conflicts of interest: none.

1 Herity B, Hynes M, Barry J. Cancer, Ireland and the EC. Dublin: Royal College of Physicians of Ireland, 1991.

2 Central Bank of Ireland. Economic statistics. Dublin: Central Bank, 1992

3 Greally J, O'Toole G, McCann H, et al. Monoclonal gammopathies in the West of Ireland: a preliminary study. Ir F Med Sci 1985;154:94-101.

4 Fitzgerald J, O'Flanagan F, Egan E, et al. Lymphoproliferative diseases in the West of Ireland: an epidemiological study. Ir Med f 1985;78:276-8.

5 Crowley M J. Cancer: the Irish experience. The epidemiology of cancer in Southern Ireland. Cork: Statistical Laboratory, University College Cork, 1995.

6 Census of population: small area population statistics. Dublin: Census of population: small area population statistics.
Central Statistics Office, Stationery Office, 1987.

7 O'Hare A. A note on a proposed census based Irish social O'Hare A. A note on a proposed census based Irish social
class scale for epidemiological health research. Economic class scale for epidemiological hea

8 Daly L, Herity B. Childhood leukaemia in the Republic of Ireland mortality and incidence. Dublin: Department of Health, 1986

9 Waterhouse J, Muir C, Shanmugaratham K, et al. Cancer incidence in five continents. Vol 4. Lyon: International Agency for Research on Cancer, 1982: 671-4.

10 Devesa SS, Frears T. Non-Hodgkins lymphoma time trends. United States and international data. Cancer Res Suppl 1992;52:5432-40.

11 Starr T E, Nalesnik MA, Porter KA. Reversibility of lymphomas and lymphoproliferative lesions devleoping under cytosporin-steroid therapy. Lancet 1984;i:583-7.

12 Knowles DM, Chamulak GA, Subar M. Lymphoid neoplasia associated with AIDS. The New York University Medical Centre. Experience with 105 patients (1981-1986). Ann Intern Med 1988;108:744-53.

13 Niedobitek G, Young LS. Epstein-Barr virus persistence and virus associated tumours. Lancet 1994;343:333-4.

14 Isaacson PG, Spencer J, Connoll CE, et al. Malignant histiocytosis of the intestine: a $\mathrm{T}$ cell lymphoma. Lancet 1985;ii:688-91.

15 Hyjek E, Isaacson PG. Primary B cell lymphoma of the thyroid and its relationship to Hashimoto's thyroiditis. Hum Pathol 1988;19:1315-26.

16 Parsonnet J, Hansen S, Rodriguez L, et al. Helicobacter pylori infection and gastric carcinoma. N Engl F Med 1994; 330:1267-71.

17 Council on Scientific Affairs. Council report: cancer risk of pesticides in agricultural workers. $7 A M A 1988 ; 260$ :959-

18 Wiklund K, Dich J, Holm LE, et al. Risk of cancer in pesticide applicators in Swedish agriculture. Br f Ind Med 1989; 46:809-14.

19 Blair A, Malker H, Cantor KP, et al. Cancer among farmers: a review. Scand f Work Environ Health 1985;11:397-407.

20 Weisenburger DD. Human health effects of agrichemical use. Hum Pathol 1993;24:571-6.

21 Brownson RC, Reif JS, Chang JC, et al. Cancer risks among Missouri farmers. Cancer 1989;64:2381-6.

22 Mead GM. Testicular cancer and related neoplasms. BMF 1992;304:1426-9.

23 Thornhill JA, Conroy RM, Kelly DG, et al. Recent trends in mortality due to testicular cancer in Ireland. A comparison with England and Wales. F Epidemiol Community Health 1986;40:218-22

24 Swerdlow AJ, Skeet RG. Occupational associations of testicular cancer in South East England. $\mathrm{Br} \mathcal{F}$ Ind $\mathrm{Med}$ $1988 ; 45: 225-30$

25 Sherins RJ. Are semen quality and male fertility changing? $N$ Engl f Med 1995;332:327.

26 Mills P, Newell GR, Johnson DE. Testicular cancer associated with employment in agriculture, oil and natural gas extraction. Lancet 1984;i:207-9.

27 Van den Eeden SK, Weiss NS, Strader $\mathrm{CH}$, et al. Occupation and the occurrence of testicular cancer. $A m \mathcal{F}$ Ind Med 1991;19:327-37.

28 Cusack R, Johnson G. A study of dichlorovos (Nuvan 2,2, dichloro ethynl dimethyl phosphate) a therapeutic agent for sealice (Lepeophtlemus salmosis). Report no14. Nova Scotia, Canada: ERDA, 1989. 